\title{
THE REPORT OF THE ROYAL COMMISSION ON POPULATION
}

$\mathrm{T}$ HE Royal Comm sion on Population was set up by the Coalition "hernment in March 1944, "to examine the facts relating to present population trends in Great fritain; to investigate the causes of these trends and to consider their probable consequence $;$ consider what measures, if any, should be taken the national interest to influence the future trend of population; and to make recommencations. The Commission has now issued its report*. The reports of the three committees appointed to assist it - the Economics Committee, the Statistics Committee, and the Biological and Medical Committee-together with sundry other seientific papers will be published in the near future.

The Commission's terms of reference naturally lead to a division of the report into three parts, dealing respectively with the statistical data available for the discussion of population trends, with the level of population that is desirable in the national interest and with the recommendations designed to achieve this level.

The first part, which deals with trends and probable future movements, is the best-documen ${ }^{2}$ ed section of the report. It begins by examining the history of population trends in Britain and provides a concise re-statement of the facts relating to the declining birth-rate. The Commission rejects the theory that this fall was due to a decline in the physiological capacity for reproduction, and adduces evidence that the main cause has been a considerable increase in the practice of voluntary family limitation. This fact must be borne in mind in any examination of the increase in births which has taken place in the last. few years. The Commission investigates this increase in detail in the light of published vital statistics and of yet unpublished data from the special sample family census that was taken on its behalf in 1946 . It concludes that there is evidence to show that the average size of family of married couples has recently been stabilized after a period of decline lasting for well over half a century. The Commission attaches great importance to this stabilization. It stresses, however, that while there is deliberate planning of families, stability in the ultimate size of families is not inconsistent with fluctuations in annual birth- or fertility-rates, as married couples are now able to control the spacing of their births. Thus, there is some evidence that in the early years of the war couples refrained from having children, and that part of the high number of births in the later war years and the immediate post-war period was due to a 'making-up' of these postponed births. War conditions also led to an increase in marriage-rates and to a reduction in the average age at marriage. The number of young recently married couples in the population is therefore abnormally high, and as fer,ility is highest at early durations of marriage, a large number of births $h$ ve resulted.

This increase in births is, however, unlikely to prove a permanent phenomenon. Unless there is a persistent further fall in marriage age, which is unlikely, the number of marriages will decline sharply during the next quinquennium. If the ultimate size of families remains constant at its present level of approximately $2 \cdot 25$ children per married couple,

* Royal Commission on Population. Report. (Cmd. 7695.) Pp. xii +259 . (London: H.M. Stationery Office, 1949.) 48. 6d. net. births in 1957-62 will amount to only about 80 per cent of the number taking place in 1942-47.

The Commission points out that the present age structure of the population implies a decline in the number of young adults, a growth in the number of the aged, and relative stability in the number aged fifteen to sixty-five, though the average age of the latter group will increase. If family size were to remain constant at its present level and marriage habits do not change, and mortality continues to decline, total numbers will continue to increase until about 1977-82, and there will then be a slow decline. The continuation of present trends will also imply a reduction in the excess of women, which is at present abnormally high because of the effects of past migrations and wars. The immediate consequences will not be very different even if the assump. i ions set out above are varied slightly.

The Commission feels that the traditional method of measuring population replacement by means of the net reproduction rate is unsatisfactory and liable to yield misleading results. They prefer to analyse the problem of replacement in a less mechanical way and to study movements in the average size of family of married couples. The problems involved in an analysis of this kind are examined in a technical appendix to the report prepared by Mr. W. A. B. Hopkin, the assistant secretary to the Royal Commission, and a more detailed treatment is promised in the forthcoming papers of the Statistics Com. mittee. On the basis of present family size and marriage habits, and on the assumption of a continued fall in mortality, the Commission estimates that in all probability the population is not at present replacing itself, and that the deficiency is of the order of 6 per cent.

This conclusion leads the Commission to the second part of its report, in which it discusses the level of population that would be desirable in the national interest. It believes that "the danger that a shortage of foodstuffs entering world markets may continue indefinitely to the serious detriment of countries whose populations have outstripped their own agricultural resources cannot ... be rated higher than a possibility which owing to immediate difficulties . . may appear far more probable than it really is". But there are obvious difficulties in the present position of the British balance of payments, and the Commission feels that there is a possibility that increasing imports of food and raw materials may be obtainable only on steadily deteriorating terms of trade. It is not dogmatic on this point, as it considers the present to be a very unpropitious time for making forecasts. The situation should be much clarified during the next ten years; but the Commission feels that in view of these difficulties there is reason to be "thankful that no further large increases in the population are probable".

There are, however, other unpleasant consequences associated with a declining population. The present age structure and the rise in the expectation of life make a rise in the ratio of dependants to productive workers inevitable. The proportion and number of old people is bound to increase, and the social cost of their maintenance, which consists of the excess of their consumption over their production, has almost certainly risen. It is thus desirable that 
the period of working life should be extended, and the Commission points out that some of the provisions relating to retirement pensions in the National Insurance Act are not conducive to such an extension. It makes no specific recommendation on problems of dealing with the aged, though it points out that there will be a need for increasing supplementary services which are designed to assist the infirm old.

These changes in the age structure are certain to make the economic system less flexible. An increase in the proportion of older workers will make it considerably more difficult for the younger generation to gain early promotion, and this, in turn, may lead to pressure for an earlier retiring age, which would not necessarily be in the national interest. The scarcity of labour might make it difficult to man industries which are commonly considered unattractive, and it may be necessary to draw on immigrants for that purpose. The Commission does not, however, consider that a programme of cont inuous large-scale immigration is practicable.

The Commission then proceeds to examine certain other factors which it calls 'imponderables'. It points out that Britain is the centre of a world-wide Commonwealth and that in the past she has supplied emigrants to people the British Dominions. At present, even under the most favourable assumptions, Britain could not hope to supply more than a third of the man-power requirements of the Dominions. Eut the Commission attaches even greater importance to the fact that the extension of Western values and culture depends upon the vitality of the constituent countries of Western civilization and that a declining population would be interpreted as a sign of decadence. If family size were to remain below replacement level for any length of time, a recovery to a level sufficient for replacement would become more and more diffi. cult. The Commission, therefore, has no hesitation in recommending that a replacement level of family size is desirable in Britain at the present time. It admits that it finds it difficult to weigh the various factors entering into its conclusion and that it has been strongly influenced in making its recommendation by the 'imponderable' elements in the situation. It stresses the importance of not applying a "narrow utilitarian calculus" in the consideration of population policy.

As a replacement level of family is desirable, the position of the family with children must be improved. There is a case for such an improvement on the grounds of social justice alone, and the Royal Commission's recommendations on that score are independent of the present demographic position. It feels that "in the process of social advance, until recently, the family has been overlooked, or given only a minor place in social policy", and that this position should be remedied. For this purpose the Com. mission makes a number of specific recommendations.

It is recommended that family allowances should be raised immediately from their present level of $5 s$. to $7 s$. per week, and to $10 s$. per week for children over the age of eleven. The youngest, and not as at present the oldest, child would be excluded from the operation of the scheme. Thus a family with two children, one of whom was over eleven years of age, and the other below, would draw an allowance of $10 s$. Allowances should be payable from the date when pregnancy is established, and they should be exempt from income tax. As a long-term policy the Commission recommends that the exclusion of the first child from the operation of the scheme should be abolished. As the implementation of this policy is impossible in the present financial situation, it recommends that while the present position persists a small lump-sum grant should be made on the birth of the first child to cover certain capital costs which are incurred at that time. The Commission also recommends that the introduction of contributory family allowance schemes within particular pro. fessions should be encouraged, and that the principle of children's allowances should be re-introduced in the salary scales of officers of the fighting services.

The Commission further recommends that the flat-rate system of children's allowances for income tax purposes be replaced by a system of flexible allowances consisting of an allowance amounting to 10 per cent of the first $£ 1,000$ of the parents' earned income and of an additional 5 per cent of any earned income between $£ 1,000$ and $£ 2,000$. This would give a maximum allowance of $£ 150$ for each child where the parents' income was $£ 2,000$. The minimum allowance would remain at its present level of $£ 60$.

The remaining recommendations are less specific. The Commission regards as fundamental the accept. ance of the principle of voluntary parenthood and of the freedom of married women to go out to work. It rejects the idea of building up family size by means of repressive measures, and recommends that contraceptive advice should be made available to all married persons who desire it through the National Health Service. The Service should also provide clinics for the treatment of infecundity and should promote research into problems of sterility and sub. fertility. Anæsthetics or analgæsics should be provided for all women in childbirth who desire them, and every effort should be made to reduce further the number of stillbirths and infant deaths to levels which have already been achieved in other European countries.

On the social side it is desirable that assistance should be provided for mothers of young children in the form of home helps, day nurseries and nursery schools not only in periods of emergency but also as a normal measure. Such assistance should not be free : parents would contribute to the cost of these services in proportion to their means.

In formulating housing policy, account should be taken of family needs. The Commission states that the distribution of houses by size is quite unrelated to family size. Local authorities should encourage mobility among their tenants and try to persuade families who occupy houses which are larger than they need to move into smaller dwellings. Consideration should be given to modernizing those old-fashioned houses which are likely to stay in use for a considerable further period. The Commission also recommends the appointment of an expert committee to consider the feasibility of the introduction of a system of rent rebates depending on the number of children.

Finally the Commission stresses the importance of further research into population subjects. Earlier in the report it comments on certain aspects of differ. ential fertility and on the association between family size and intelligence. It does not feel sufficiently expert to evaluate the evidence on that topic, though it directs attention to Sir Godfrey Thomson's Scottish survey, the results of which do not at first sight lend support to the hypothesis that intelligence is declining. The Commission recommends that further research on this subject be carried out. It also makes certain recommendations for improving the collection and analysis of fertility statistics in Great Britain and for 
the inclusion of fertility questions in the national census at regular intervals. Details of these proposals will be published in the papers of the Statistics Committee.

The Commission does not recommend that a new body dealing with population research should be set up. It thinks that the existing Interdepartmental Committee on Social and Economic Research should have its powers suitably extended to supervise this work, and that the Lord President of the Council should be the Minister responsible for a continuous watch on population movements and their bearing on national policies.

E. GrebenIK

\section{sop \\ CHROMATOGRAPHIC SEPARATION OF NATURAL COMPOUNDS}

\author{
By DR. A. H. COOK
}

Imperial College of Science and Technology, London

$\mathrm{T}$ $\mathrm{HE}$ isolation of

pound natural comextraction, distill ation, crystallization-and combinations and refplonents of these methods. The problem of isolating, less abundant natural substances is associated $f_{\text {with }}$ two outstanding difficulties. The scalof the extraction process is much greater, and the dred material is often accompanied by a variety of very similar materials. Without doubt chromatography has done more than any other experimental advance to overcome these difficulties.

\section{Simple Chromatography}

Chromatography is in its simplest form a method of separation of a mixture into its components, from solution, by virtue of their different affinities for a selected adsorbent. The method, first described in its commonest modern form by Tswett ${ }^{1}$, is often carried out in a column of adsorbent through which the solution is made to percolate, its passage being assisted by pressure or suction. Theoretical concepts and practical aspects have been many times considered $^{2}$; but owing to the many variables involved in even the simplest separation, theoretical considera. tions in the physico-mathematical sense have had singularly little effect on practical procedure. It is perhaps only necessary to say that as more solution percolates through the column, often followed by a pure solvent, one may visualize the individual components of the mixture being alternately adsorbed on and eluted off from particle to particle of adsorbent ; they thus appear to move down the column at rates depending primarily on their separate affinities for the adsorbent, and ultimately are located in more or less separated zones. It was this visual demonstration of the individual components of a coloured mixture, when spread out on an adsorbent column in a manner reminiscent of a spectrum, which suggested the term 'chromatogram'.

To isolate the adsorbed compounds in the ideal instance it is only necessary to dissect the column mechanically, break the adsorption complex by washing the separated sections of the adsorbent column with a selected solvent, and recover by crystallization or otherwise the pure compounds from the respective filtrates. In completely unknown cases some small exploratory experiments are often desir-

* Substance of a discourse at the Royal Institution, delivered on May 25. able to select a solvent which will permit the required resolution, for adsorption depends markedly on the polar nature of the solvent; often again the components have such different adsorption affinities that one or more of them may completely traverse the column while others remain in the adsorbed state; in such instances the term 'liquid chromatogram' is sometimes used, for the components appear separately in succeeding fractions of the eluate. The examination of leaf pigments and of egg pigments affords simple examples of the general process applied to natural material. Naturally, when the mixture is very complex, the resolution of the adsorption zones may be less complete in a column of reasonable size, and the eluate may change gradually rather than sharply, so that it may be desirable to collect a very large number of fractions and examine them systematically to elucidate the nature of the mixture. At least one mechanical device has been used to facilitate this, and a commercially available machine enables one to collect any predetermined number of fractions up to two hundred, each fraction being of predeterm. ined magnitude controlled by photo-electrically counting individual drops.

So far, the separation of visible compounds only has been mentioned; but the principles apply equally to colourless substances, it being only necessary to adopt some means of locating the adsorption zones.

Many adsorbed compounds are easily detectable by virtue of their fluorescence in ultra-violet light; others reveal themselves on an adsorption column by their quenching the fluorescence of, or perhaps displacing, a highly fluorescent indicator which is incorporated in the adsorbent, the different component zones thus appearing dull against a more fluorescent background ${ }^{3}$. Inorganic fluorescent materials such as zinc sulphide may be used instead of an organic indicator ${ }^{4}$, and the general process is illustrated by the chromatography of such diverse materials as flower petal pigments, of the antibiotic terrein, and of infusions of coffee which show chroma. tographic behaviour characteristic of the origin of the coffee bean. Still again, colourless mixtures may often be separated by converting them into coloured derivatives which are then chromatographed, and if these devices all fail, one may always carry out the process empirically, repeating it if necessary according to the degree of purity found in the recovered frac. tions; almost innumerable separations of such materials as steroids, sex hormones and their degradation products have been examined in this way on a microscale, notably in the hands of Reichstein and his collaborators.

It is clearly an advantage of chromatography that it is applicable to almost any natural material, with certain occasional special provisions, it is true, but with little reference to the complexity of the materials being examined. Almost innumerable natural materials have been thus examined, including carotenoids and other natural pigments, vitamins, drugs, wines, fruit extracts, etc., giving pictorial separations which can be turned to use, for example, in purely qualitative and quantitative examinations, in absolute identifications, or in detecting impurities or adulterations.

\section{Some Advances in Pure Chromatography}

Many of the applications mentioned so far have been to the isolation of specific compounds, a task for which chromatography is admirably adapted because of the surprising dependence of adsorption on structure. For example, the chemist looks to 